\title{
Differences in the association of subjective wellbeing measures with health, socioeconomic status, and social conditions among residents of an Eastern Cape township
}

\author{
Jane M. Cramm • Anna P. Nieboer
}

\begin{abstract}
Objective: The use of variably self-reported measures of wellbeing may produce differing outcomes. This study examined the differences in association with health, socioeconomic status, and social conditions (marital status, social capital) of two widely used cognitive subjective wellbeing measurements: Cantril's ladder and Diener's five-item Satisfaction with Life Scale. Methods: A stratified sampling design was used to collect data from representative households in the 20 neighborhoods of Rhini, a deprived suburb of Grahamstown in the Eastern Cape province of South Africa. Correlation and stepwise multiple regression analyses investigated differences in the associations between wellbeing and health, demographics, socioeconomic status, and social conditions determined by the three measurements. Results: We found that the multiple-item satisfaction with life scale elicited more discriminating responses that took into account a broader range of life domains. This scale reported more significant relationships between subjective wellbeing and health, socioeconomic status, and social conditions. Cantril's ladder produced a narrower range of career-like comparisons. The direction of association between measures of wellbeing and socioeconomic characteristics never changed according to the measures used. Conclusions: Policy-makers, researchers, and practitioners using these instruments should be aware of the differences between single- and multiple-item wellbeing measures, and recognize that the choice of instrument will affect the life domains found to be associated with wellbeing.
\end{abstract}

Keywords: wellbeing, measurement, social indicators, socioeconomic, Satisfaction with Life Scale

\section{Introduction}

The study of subjective wellbeing (SWB) is growing exponentially (Kahneman, 1999). SWB is "a broad category of phenomena that includes people's emotional responses, domain satisfactions, and global judgments of life satisfaction"; it thus differs from happiness, although the terms are often used synonymously (Diener, Suh, Lucas, \& Smith, 1999: 277). Questions concerning SWB are increasingly included in population surveys, reflecting the emergence of a new science of SWB. Scholars in a wide range of disciplines have recently attempted to define, measure, and analyze SWB in various contexts (Hoorn, 2007). Some researchers have brought attention to the importance of the analytical and empirical separation of various forms of SWB (Diener, Kahneman, Tov, \& Arora, 2010; Lucas, Diener, \& Suh, 1996). 
Measures of SWB are obtained through self-reporting: respondents are asked to evaluate their lives as a whole or some aspect thereof. Kahneman (1999) described a major distinction between global evaluative judgments and people's cumulative feelings of pleasure and displeasure. Specifically, reported SWB consists of two distinctive components (Diener 1994: 106): an affective component, which refers to the presence of positive affect and the absence of negative affect, and a cognitive component. The affective component is a hedonic evaluation guided by emotions and feelings, whereas the cognitive component is an information-based appraisal of one's life with respect to an envisioned "ideal" life. A global measure of "life satisfaction" taken at a single point in time may be more heavily weighted with judgment and cognition, whereas reported happiness may be more saturated with affect. SWB measures with an affective component ascertain how often an individual reports experiencing positive or negative affect (such as smiling or crying). In contrast, life satisfaction is more broadly measured: an individual's satisfaction with life is assessed in general and in various life domains (e.g., health, employment, income, social conditions) (Diener, 1994). This distinction implicitly requires the researcher to collect separate measurements of affective experience and life satisfaction, and to conduct separate analyses of their determinants.

Most discussion of the need for SWB measures has focused on cognitive/judgmental life evaluations, rather than affective measures, because they are considered to be direct measures of overall SWB. These measures are sufficiently reliable to allow multiple individual responses to be averaged, providing summary measures of SWB in neighborhoods, cities, regions, and countries, and across population sub-groups. Changes in the balance of SWB made visible by regular reporting are likely to guide the thinking of policy-makers and those affected by policy implementation. SWB measures allow an improved understanding of the elements that lead to a better life and clearer insights into the links between policies and SWB.

Diener and colleagues (2010) investigated SWB measures at both ends of the cognitionaffect continuum and found that different measures led to different outcomes. Affect-oriented questions were typically less related to income than were cognitive questions. A variety of measurement techniques may be employed to assess SWB on the cognitive side of the continuum, which may also produce differing outcomes. This study therefore compared two widely used measures at the cognitive side of the continuum.

Cantril's ladder and Diener's Satisfaction with Life Scale (SWLS) are two of the most commonly used cognitive SWB measures (Bartels \& Boonsma, 2009; Bjørnskov, 2010; Kashdan, 2004). They differ in the framing of satisfaction questions and the anchoring of responses. Cantril's technique asks respondents to rate satisfaction with life on a scale anchored by selfidentified minimum and maximum values. It solves the problem of evaluating absolute satisfaction on a closed scale by anchoring answers within an individual's conception of their best possible life. In other words, the question prompts an individual evaluation of the respondent's position in his/her life relative to where s/he would ideally like to be (Larsen \& McKibban, 2008; Stutzer, 2004). The use of a ladder technique may thus infuse respondents' answers with aspirations for and expectations of the future to a greater degree than is the case with the use of the SWLS. The respondent's relative ranking of himself/herself on this ladder may indirectly reflect differences in his/her access to scarce resources (e.g., income) more than it addresses differences in social conditions. We thus hypothesize that these two cognitive SWB measures will correlate differentially with known SWB indicators.

Cantril's ladder and Diener's SWLS also differ methodologically. Early measures of SWB, such as Cantril's ladder, were often single-item instruments. More complex, multiple-item measures of SWB and life satisfaction are often desirable. The multiple items in Diener's SWLS 
solicit responses from individuals about the extent to which they agree or disagree with statements designed specifically to capture satisfaction with life (Pavot \& Diener, 1993). Nevertheless, single-item measures have dominated large-scale surveys, many of which have relied on general and simple life satisfaction questions, such as Cantril's ladder (Blanchflower \& Oswald, 2004). Although these simpler single-item instruments have been proven to be reliable and valid SWB measurements (Pavot \& Diener, 1993), their reliability is typically lower than that of multiple-item measures.

Although some research has indicated that multiple-item life satisfaction scales provide a more structured frame of reference than single-item questions, the presence and degree of associations between health, socioeconomic status, and social conditions measured by these SWB instruments are currently unknown. Using multiple-item measures of SWB, the SWLS is expected to identify a more broadly conceived wellbeing containing a larger variety of indicators than single-item SWB measurements. We therefore additionally hypothesize that the more complex, multiple-item SWLS will lead to identification of a broader range of SWB indicators than will Cantril's ladder.

This study thus used Cantril's ladder and Diener's five-item SWLS to investigate whether these two widely used cognitive SWB measures lead to different associations with known SWB indicators. Our primary aims were to determine whether the two SWB measures showed the associations expected based on previous research, whether they performed differently, and whether differences in the strength of associations with conditions known to affect SWB (e.g., health, socioeconomic status, social conditions) could be identified. The study used data gathered in Rhini, a small township of Grahamstown, in the Eastern Cape province of South Africa. This community is characterized by poverty, unemployment, and low income levels (Cramm \& Nieboer, 2011a; Cramm, Koolman, \& Nieboer, 2011; Cramm \& Nieboer, 2011b; Møller \& Erstad, 2007; Møller, Erstad, \& Zani, 2009). Rhini has a mean SWB score of 4.6 on the 10-point Cantril's ladder (Møller, 2007), which is substantially lower than that reported for the whole nation of South Africa (5.7; Marks, Abdallah, Simms, \& Thompson, 2006). The population of Rhini can serve as a case study for policy makers and development organizations aiming to improve the SWB outcomes of people living in economically- and health-deprived regions, such as the Eastern Cape (Noble, Barnes, Wright, \& Roberts, 2010).

\section{Methods}

\subsection{Participants and Sampling}

This study applied a neighborhood-level stratified sampling design that randomly selected households in proportion to the total number of households in each of Rhini's 20 neighborhoods. Moving systematically through the neighborhood from a randomly defined starting point, the researchers selected every tenth household for inclusion in the sample. This method ensured that all households in all neighborhoods of Rhini stood an equal chance of being included in the survey.

Eligible respondents were identified in each target household; they were at least 18 years of age and had resided in Rhini for at least six months of the past year. One respondent per target household was selected using a Kish grid to ensure that all eligible persons in the household stood an equal chance of being included in the survey. The respondent was then interviewed and SWB was assessed using both measures. If this person was not available, arrangements were made to conduct the interview at a later time. Up to four attempts were made to interview selected respondents. An interview was obtained in 1,020 of the 1,042 (97.9\%) targeted households. Reasons for not achieving an interview included not finding the respondent at 
home after four visits to the household, old age or poor health, and disinterest or unwillingness.

Staff from Development Research Africa, a well-known organization experienced in undertaking national probability-based samples in deep rural and urban areas, administered the questionnaires. The interviewers gathered demographic information about the participants, such as gender, age, health status, education level, living arrangements, and employment, in addition to the SWB measures. A detailed description of this study population can be found in Møller (2007, 2008) and research of Møller and colleagues (2011), Cramm, Møller, Finkenflügel, \& Nieboer (2010), Cramm, van Exel, Møller, \& Finkenflügel (2010), and Cramm, Møller, \& Nieboer (2010a, b).

\subsection{Subjective Wellbeing Measurements}

Cantril's ladder was the framed single-item measure of SWB used to assess respondents' satisfaction with life. Respondents were asked to rate their lives in comparison to the best and worst possible lives they could imagine, on a scale of zero (worst possible life) to ten (best possible life) (Cantril, 1965). Respondents were asked, "On which step of the ladder would you say you personally feel you stand at this time?"

The SWLS was the structured multiple-item measurement used to assess respondents' satisfaction with life. This instrument consists of five items ("In most ways my life is close to my ideal"; "The conditions of my life are excellent"; "I am satisfied with my life"; "So far I have gotten the important things I want in life"; "If I could live my life over, I would change almost nothing") to which respondents rated their level of agreement on a five-point scale $(1=$ strongly disagree; 2 = disagree; 3 = neither agree/disagree; 4 = agree; 5 = strongly agree) (Pavot \& Diener, 1993). Cronbach's $\alpha$ for the SWLS used in this study was 0.88 , indicating that the scale was reliable.

Multiple items provide a more discriminating response scale than single-item SWB measurements. For example, a measure containing three items (i) with seven-point response scales (r) has 343 (ri) unique response patterns and 19 possible total scores $(\mathrm{i} \times \mathrm{r}-[\mathrm{i}-1]$ ) (Bergkvist \& Rossiter, 2007). The relatively large number of total scores makes it possible to "make relatively fine distinctions among people" (Churchill, 1979: 66) or to categorize people into a large number of groups (Bernstein, 1994: 67). A multiple-item predictive measure should thus show an increased association with the outcome measure; that is, it should exhibit higher predictive validity. The multiple-item SWLS has been shown to have favorable psychometric properties, including high internal consistency, temporal reliability (Diener, Emmons, Larsen, \& Griffen, 1985a), internal reliability (Cronbach's $\alpha=0.87$ ), and test-retest correlations (2-month stability coefficient = 0.82; Diener, Horwitz, \& Emmons, 1985b).

\subsection{Indicators of Subjective Wellbeing (self-reported)}

Health, socioeconomic status, and social conditions have been identified as potential indicators of SWB (Ahuvia \& Friedman, 1998; Andrews \& Withey, 1976; Campbell, Converse, \& Rodgers, 1976; Clark \& Oswald, 1994; Cramm et al., 2010a; Diener et al., 1985a). Studies have consistently found a high positive correlation between SWB and health (Diener \& Biswas-Diener, 2002; Diener \& Scollon, 2003; Dolan, Peasgood, \& White, 2008; Frey \& Stutzer, 2002; Hoorn, 2007). Individuals reporting higher levels of SWB tend to live longer than those with lower SWB outcomes. Good health is probably both a cause and an effect of high SWB levels (Diener \& Biswas-Diener, 2002). 
This study measured self-rated health, which is considered a valid and robust measure of general health status (Idler \& Benyamanini 1997; Mossey \& Shapiro 1982; Wen, Browning, \& Cagney, 2003). A large body of evidence has demonstrated that self-reported health assessment has high predictive validity for mortality, physical disability, and chronic disease status. Furthermore, self-assessed health is a stronger predictor of mortality than physician-assessed health (Idler \& Benyamanini, 1997; Idler \& Kasl, 1995; Mossey \& Shapiro, 1982). As a measure of health status, it captures personally experienced physical problems that may impair SWB (Wen et al., 2003). Respondents were asked, "How would you describe your health these days?" Respondents could rate their level of agreement on a five-point scale $(1=$ very poor; $2=$ poor; 3 = average; 4 = good; 5 = very good).

Much early research focused on the relationship between SWB and socioeconomic factors, such as education, employment, and income (Diener \& Biswas-Diener, 2002). Evidence for the impact of education on SWB has been mixed. Some researchers (Diener \& Scollon, 2003; Frey \& Stutzer, 2002) have suggested a positive relationship, whereas a study conducted with an English population (Clark \& Oswald, 1994) found a negative impact that may be due to changing aspirations and the creation of expectations for a higher income. It remains unknown whether such findings are applicable to more deprived populations. Education is closely correlated with income, occupational status, and social class; these factors have likely influenced the results of these studies. Unemployment shows a consistently negative association with SWB that has been suggested to have severe long-term negative impacts (Clark \& Oswald, 1994; Hoorn, 2007). Extensive research on the relationship between income and SWB has revealed that individuals with high incomes have better SWB outcomes than those with low incomes (Cramm et al., 2010b; Diener \& Biswas-Diener, 2002; Easterlin 1974; Fahey, Whelan, \& Maitre, 2005; Keck \& Krause 2007).

This study assessed income by asking respondents their average monthly household income (in South African Rand: 0-100; 101-200; 201-500; 501-750; 751-1,000; 1,001-1,500; 1,5012,$000 ; 2,001-3,000 ; 3,001-4,000 ; 4,001-5,000 ; 5,001-6,000 ; 6,001-7,000 ; 7,001$ or higher). To assess education, respondents were asked to state their highest educational level (none or some primary; some secondary; completed secondary and/or postsecondary).

Social conditions also affect SWB. Most married people report higher levels of SWB than do single people (Diener \& Scollon, 2003; Frey \& Stutzer, 2002; Hoorn, 2007). Social capital is also increasingly acknowledged to be an important social determinant of SWB (Bjørnskov, 2003, 2005; Easterlin, 2000; Grootaert, 2002; Haggerty et al., 2001; Wilkinson \& Pickett, 2006; Yip, Sybramanian, Mitchell, Lee, Wang, \& Kawachi, 2007). This factor is defined as "the set of cooperative relationships between social actors that facilitate collective actions" (Requena, 2003: 331). The core components of social capital are civic engagement and mutual trust among community members. Social capital shelters people from the harmful effects of unemployment and poverty (Camfield \& Skevington, 2008; Cramm et al., 2010b; Winkelman, 2009). People with friendly, helpful, and trustworthy neighbors tend to report higher levels of SWB than those who are more solitary (Wilkinson \& Pickett, 2006). Marks, Abdallah, Simms, \& Thompson's (2006) investigation of the correlation between social capital and SWB also indicated a relationship between greater social capital and higher life satisfaction.

We assessed social capital with three items ("People in this neighborhood are friendly"; "People in this neighborhood help each other without having to be asked"; "People in this neighborhood trust their neighbors") to which respondents rated their level of agreement on a four-point scale ( 1 = very dissatisfied; 2 = dissatisfied; $3=$ satisfied; 4 = very satisfied). The Cronbach's $\alpha$ of this scale was 0.87 . The questionnaire further probed factors previously 
implicated as potential predictors of SWB, such as unemployment (yes/no) and marital status (married/living together; single/divorced/widowed).

\subsection{Statistical Analysis}

Descriptive statistics are reported as mean values and standard deviations (SDs). Correlation analyses were performed to detect significant associations between the two cognitive SWB measures and the domains of health, socioeconomic status, and social conditions. Regression analyses were performed to identify any life domains that predicted responses to each of the measures, and to examine the differences in SWB scores obtained with the two measures. We tested the equality of the covariance matrices with the null hypothesis that the observed matrices of the SWLS and Cantril's ladder would be equal. All statistical analyses were performed with Statistical Package for the Social Sciences (SPSS) software (ver. 17, SPSS Inc., Chicago, IL, USA).

\section{Results}

Table 1 provides descriptive summary statistics (mean \pm SD) for the dependent and independent variables of SWB. One-third (33\%) of the respondents were married and the others were single, widowed, or separated/divorced. Thirty-five percent of respondents had no formal schooling or had received only primary education. Forty percent had received some secondary education and $25 \%$ had matriculated and/or received postsecondary education. Sixty-two percent of the respondents were unemployed.

Table 1. Descriptive statistics for the variables used in the correlation and multiple regression analyses $(\mathrm{N}=1020)$.

\begin{tabular}{lllll}
\hline & Mean & SD & Min & Max \\
\hline Cantril's ladder & 4.63 & 2.07 & 0.00 & 10.00 \\
Satisfaction with life scale & 2.62 & 0.86 & 1.00 & 5.00 \\
Health & 3.55 & 1.01 & 1.00 & 5.00 \\
Income & 1,250 & 2.13 & 0,000 & $>7,001$ \\
Social capital & 2.97 & 0.54 & 1.00 & 4.00 \\
\hline
\end{tabular}

Table 2 shows the univariate effects of health, unemployment, education, income, marital status, and social capital on SWB scores obtained with Cantril's ladder and the SWLS. We found that health, unemployment, education, income, and social capital were associated with Cantril's ladder scores (all $p \leq 0.001)$, followed by marital status $(p \leq 0.05)$. All independent variables were associated with the SWLS (all $p \leq 0.001$ ). The direction of association between measures of wellbeing and socioeconomic characteristics never changed according to the measures used. 
Table 2. Correlations between independent variables and subjective wellbeing $(N=1020)$.

\begin{tabular}{llllllll}
\hline & 1 & 2 & 3 & 4 & 5 & 6 & 7 \\
\hline Patient & & & & & & & \\
1. health & & & & & & & \\
2. unemployment & $-0.26^{* * *}$ & & & & & & \\
3. education & $0.39^{* * *}$ & $-0.22^{* * *}$ & & & & & \\
4. income & $0.11^{* * *}$ & $-0.50^{* * *}$ & $0.22^{* * *}$ & & & & \\
5. married & -0.03 & $-0.12^{* * *}$ & -0.06 & $0.08^{*}$ & & & \\
6. social capital & $0.08^{*}$ & -0.02 & -0.03 & 0.01 & 0.02 & & \\
7. Cantril's ladder & $0.11^{* * *}$ & $-0.21^{* * *}$ & $0.10^{* * *}$ & $0.26^{* * *}$ & $0.08^{* * *}$ & $0.08^{*}$ & \\
$\begin{array}{l}\text { 8. Diener's } \\
\text { satisfaction with }\end{array}$ & $0.17^{* * *}$ & $-0.15^{* * *}$ & $0.13^{* * *}$ & $0.17^{* * *}$ & $0.13^{* * *}$ & $0.16^{* * *}$ & $0.41^{* * *}$ \\
life scale & & & & & & & \\
\hline Netes: $p \leq 0.05 ; * x \leq 0.01^{* * *} p \leq 0.001$. & & & & & \\
\hline
\end{tabular}

Notes: ${ }^{*} p \leq 0.05 ;{ }^{* *} p \leq 0.01 ;{ }^{* * *} p \leq 0.001$.

Regression analysis revealed that unemployment was weakly associated with SWB determined by Cantril's ladder, and showed no association with SWB determined by the SWLS (Table 3). The observed covariance matrices of the two instruments were equal. Comparison of the SWLS and Cantril's ladder showed strong associations between SWB and income (both $p \leq 0.001$ ); analysis of covariance matrix equality revealed that the relative strength of this association did not differ significantly between measures (Cantril's ladder: $\beta=0.20$; SWLS: $\beta=0.13$ ).

Table 3. Comparison of scores produced by the cognitive wellbeing measurements in the domains of health, socioeconomic status, and social conditions.

\begin{tabular}{lll}
\hline & Cantril's ladder $(\beta)$ & $\begin{array}{l}\text { Satisfaction with } \\
\text { life scale }(\beta)\end{array}$ \\
\hline Health & 0.05 & $0.12^{* * *}$ \\
Unemployment & $-0.08^{*}$ & -0.03 \\
Education & 0.03 & 0.06 \\
Income & $0.20^{* * *}$ & $0.13^{* * *}$ \\
Married & 0.06 & $0.12^{* * *}$ \\
Social capital & $0.07^{*}$ & $0.15^{* * *}$ \\
Adjusted $\mathrm{R}^{2}$ for & 0.11 & 0.12 \\
equation & & \\
\hline
\end{tabular}

Notes: ${ }^{*} p \leq 0.05 ;{ }^{* *} p \leq 0.01 ;{ }^{* *} p \leq 0.001$.

Further comparison revealed additional differences in the results obtained with the two instruments. SWLS scores indicated that health was significantly related to SWB $(\beta=0.12 ; p \leq$ 0.001), whereas Cantril's ladder scores did not. Moreover, analysis of covariance matrix 
equality showed that the relative strength of indicators differed significantly between measures $(p \leq 0.001)$ for this variable. The results for social capital and marital status also differed between measures. Cantril's ladder scores indicated a weak association between SWB and social capital $(\beta=0.07 ; p \leq 0.05)$ and no association with marital status; SWLS scores indicated the strongest associations with these social domains of SWB (marital status: $\beta=0.12, p \leq 0.001$; social capital: $\beta=0.15, p \leq 0.001)$. The test for the equality of the covariance matrices showed that the relative strength of both indicators differed significantly between measures (marital status: $p \leq 0.05$; social capital: $p \leq 0.001$ ). Neither measure found education to be significantly related to SWB in this poor community. In the univariate analyses described above, however, education was significantly related to SWB by both measures. We found no difference in the instruments' explained level of variance (Cantril's ladder: $\beta=0.11$; SWLS: $\beta=0.12$ ).

\section{Discussion}

This study investigated whether two widely used cognitive/judgmental measures of SWB (Cantril's ladder and Diener's SWLS) were differentially associated with the life domains of health, socioeconomic status, and social conditions. We hypothesized that cognitive SWB measures correlated differentially with known SWB indicators, postulating that a more complex, multiple-item SWLS would lead to the identification of a broader range of SWB domains than would a single-item measure (Cantril's ladder). As expected, the employment of different measurement techniques to assess SWB produced differing outcomes. Our first hypothesis, that these two cognitive SWB measures correlate differentially with known SWB indicators, can be confirmed. These findings are important for policy-makers who seek to evaluate policies based on SWB outcomes over time.

Although Cantril's ladder did not find health to be associated significantly with SWB, multivariate analyses of SWLS results did find such an association. Moreover, the relative strength of health differed significantly between measures. Unemployment was significantly associated with SWB as measured by Cantril's ladder, but not as measured by the SWLS. These findings indicate that data produced by the administration of slightly different questions, or of similar questions asked under slightly different conditions, can differ substantially. The difference between "life satisfaction domains" and "best possible life" led to significantly different responses.

The two cognitive SWB measures thus tapped into two different concepts of satisfaction. This difference may be due to the cognitive processes that occurred during the administration of these instruments. Cantril's technique asks respondents to rate satisfaction with life on a scale anchored by self-identified aspirations and ideals (Larsen \& McKibban, 2008; Stutzer, 2004), which may elicit more aspirational responses. The aspirations and expectations of the poor residents of Rhini are related to income, employment, and social capital, all of which are particularly scarce in this township. Health, education, and marriage appear to be less influential in shaping their future expectations. People may consider these resources to be more stable over time, and although their control over income, employment, and social capital is likely to be limited, their aspirations to improve their socioeconomic and social conditions explain the variation in SWB levels among respondents. The framework defined by the best and worst possible lives may trigger career-like comparisons in which income and employment are more important than, for example, health.

The relationship between SWB and unemployment differs strikingly between measures. Cantril's ladder found a strong significant association between SWB and unemployment, whereas the SWLS found no significant association. Unemployment is widely considered to 
generate negative externalities. Higher unemployment rates lead the employed to feel less secure about keeping their job in the future, while the unemployed suffer from worse prospects of finding a new job. In addition to these negative effects, however, the unemployed may experience a counteracting positive impact termed the "social norm effect of unemployment": one's own unemployment may be easier to bear when more people suffer the same fate (Kessler Turner, J., \& House, 1988; Cohn, 1978). This may be due to the reduced stigmatization of unemployment in such situations. For example, Kessler and colleagues (1988) found that the unemployed established social contacts more easily when others in the local area were also unemployed. Cohn (1978) found that unemployed persons' satisfaction with self was lower when unemployment could not be attributed to an external cause, such as generally high unemployment rates in a region. Clark (2003) found that the SWB of the unemployed rose with the regional unemployment rate, even at the household level; people reported higher SWB scores when they were not the only unemployed person in the household. Similar results have been found for the United Kingdom (Shields \& Wheatley Price, 2005), Australia (Shields, Wheatley Price, \& Wooden, 2008), South Africa (Powdthavee, 2007), and Switzerland (Stutzer \& Lalive, 2004).

Our findings suggest that social norms were a more important component of responses produced with the SWLS than of those elicited by Cantril's ladder. The SWLS appears to be more susceptible to the wider context of social norms within the community than Cantril's ladder. It incorporates factors such as high unemployment, which results in less social disapproval, and other sources of SWB, such as a partner who provides social approval. For this reason, social domain indicators appeared to be more important in the SWLS results than in those obtained with Cantril's ladder. The relative strengths of marriage and social capital were also significantly higher when measured by the SWLS. When a respondent is asked to consider multiple aspects of life, social norms and social approval, such as behavioral confirmation and affection, may become more important in his/her consideration of SWB. Consequently, health, social capital, and marriage are visible as important SWB indicators in the results of multiple-item instruments. In contrast, asking a respondent about the "best possible life" using Cantril's ladder may elicit a response based more on (economic) status than on social norms.

The SWLS questions asked respondents to consider a broader scope of life satisfaction than did Cantril's ladder. Whereas Cantril's ladder triggers career-like comparisons focused mainly on income and employment, the SWLS produced responses indicating significant relationships with a larger variety of domains, such as health, socioeconomic status, social conditions, and SWB. Thus, we can also confirm our second hypothesis, that a more complex multiple-item SWB measure would identify a broader range of SWB indicators than a single-item SWB measure. Although we expected that the multiple-item SWLS would show higher predictive validity, the two SWB measures showed equal degrees of explained variance.

Some limitations must be considered when interpreting our study findings. Given the location of our study in the community of Rhini, our results may apply only to similarly economically deprived regions. Within-nation comparisons typically result in small but significant correlations between income and SWB. In studies using large population samples, Diener and Oishi (2000) compared 19 nations, finding a mean correlation coefficient of 0.13 , and Lachman and Weaver (1998) found similar results in a study of the United States (0.18). In our study, the mean correlation coefficients measured with the SWLS (0.17) and Cantril's ladder (0.26) differed significantly $(p \leq 0.05)$. Income has been found to be relatively more important for SWB in economically deprived regions, such as the community of Rhini (Diener, Sandvik, 
Seidlitz, \& Diener, 1993). Neither measure found education to be a strong determinant of SWB in the Rhini sample. Because the majority of respondents $(75 \%)$ had received none or only some primary or secondary education, these results likely reflect the deprived situation of the community as a whole. Another limitation of the study's community-level location is the relatively low explained variance. As with previous studies (Ahuvia \& Friedman, 1998; Diener \& Biswas-Diener, 2002), we found that factors such as income, employment, education, and marital status accounted for only a small amount of variance in SWB. Although previous research defined six broad groups of SWB determinants (personality, contextual and situational, demographic, institutional, environmental, and economic factors; Hoorn, 2007), we included only health, demographics, socioeconomic status, and social conditions in the present study. Exclusion of the other determinants may in part have caused the relatively low explained variance. Further, objective indicators are often not strongly associated with SWB, because of substitution processes and buffer effects. People are resourceful in substituting across different life-domains and different forms of wellbeing (Nieboer \& Lindenberg, 2002). Cantril's ladder and the SWLS use direct questions of wellbeing focusing on very general dimensions of wellbeing, which has its disadvantages. Direct wellbeing questions are criticized because individuals are biased by their present state and what they remember at that moment (Kahneman, 1999; Nieboer, Lindenberg, Boomsma, \& Van Bruggen, 2005). One can try to identify the major dimensions of SWB and ask questions that refer to activities and experiences related to these dimensions avoiding direct questions on wellbeing (Nieboer et al., 2005) and opening up possibilities to pinpoint alternative means for the realization of SWB. These alternative means help us say something about which means are more essential (i.e., less substitutable) than others (Diener \& Lucas, 2000).

\section{Conclusion}

This research has provided preliminary insight into the issues that may emerge with the use of different self-reported cognitive measures of SWB. The direction of association between measures of wellbeing and socioeconomic characteristics never changes according to the measures used. However, our findings revealed that the multiple-item SWLS provided a more discriminating response scale that took into account a broader scope of life domains and found the most significant relations between SWB and health, demographics, socioeconomic status, and social conditions. Cantril's ladder elicited responses with a narrower focus characterized mainly by career-like comparisons. Since many other researchers have found SWB to be associated with health, it is striking that multivariate analysis of the Cantril's ladder data found no such association. Further longitudinal studies, including those conducted in less-deprived communities, are necessary to confirm our findings. Researchers and practitioners using these measures should be aware of the differences between single- and multiple-item SWB measurements and recognize that the choice of SWB instrument will affect the relationships found between life domains and SWB.

\section{Acknowledgments}

This research project was funded by the South Africa Netherlands Research Programme on Alternatives in Development (SANPAD). The views expressed in the paper are those of the authors. The authors declare that they have no competing interests.

\section{Authors}

Jane M. Cramm 
Erasmus University (iBMG)

cramm@bmg.eur.nl

Anna P. Nieboer

Erasmus University (iBMG)

nieboer@bmg.eur.nl

\section{Publishing Timeline}

Received 16 December 2011

Accepted 13 March 2012

Published 29 April 2012

\section{References}

Ahuvia, A. C., \& Friedman, D. (1998). Income, consumption, and subjective well-being: Toward a composite macromarketing model. Journal of Macromarketing, 18, 153-168. http://dx.doi.org/10.1177/027614679801800207

Andrews, F. M., \& Withey, S. B. (1976). Social Indicators of Well-Being: America's Perception of Life Quality. New York, NY: Plenum.

Bartels M., \& Boomsma, D. I. (2009). Born to be happy? The etiology of subjective well-being. Behavior Genetics, 39, 605-615. http://dx.doi.org/10.1007/s10519-009-9294-8

Bergkvist, L., \& Rossiter, J. R. (2007). The predictive validity of multiple-item versus single-item measures of the same constructs. Journal of Marketing Research, XLIV, 175-184. http://dx.doi.org/10.1509/jmkr.44.2.175

Bernstein, I. H. (1994). Psychometric Theory. $3^{\text {rd }}$ ed. New York: McGraw-Hill.

Bjørnskov, C. (2003). The happy few: Cross-country evidence on social capital and life satisfaction. Kyklos, 56, 3-16. http://dx.doi.org/10.1111/1467-6435.00207

Bjørnskov, C. (2005). The multiple facets of social capital. European Journal of Political Economy, 22, 22-40.

Bjørnskov, C. (2010). How comparable are the Gallup World Poll life satisfaction data? Journal of Happiness Studies, 11, 41-60. http://dx.doi.org/10.1007/s10902-008-9121-6

Blanchflower, D. G., \& Oswald, A. J. (2004). Well-being over time in Britain and the USA. Journal of Public Economics, 88, 1359-1386. http://dx.doi.org/10.1016/S0047-2727(02)00168-8

Camfield, L., \& Skevington, S. M. (2008). On subjective well-being and quality of life. Journal of Health Psychology, 13, 764-775. http://dx.doi.org/10.1177/1359105308093860

Campbell, A., Converse, P. E., \& Rodgers, W. L. (1976). The Quality of American Life. New York, NY: Russell Sage.

Cantril, H. (1965). The Pattern of Human Concerns. New Brunswick, NJ: Rutgers University Press.

Churchill, G. A. (1979). A paradigm for developing better measures of marketing constructs. Journal of Marketing Research, 16, 64-73. http://dx.doi.org/10.2307/3150876

Clark, A. E. (2003). Unemployment as a social norm: Psychological evidence from panel data. Journal of Labor Economics, 21, 323 -351. http://dx.doi.org/10.1086/345560

Clark, A. E., \& Oswald, A. J. (1994). Unhappiness and unemployment. Economic Journal, 104, 648-659. http://dx.doi.org/10.2307/2234639

Cohn, R. (1978). The effect of employment status change on self-attitudes. Social Psychology, 41, 81-93. http://dx.doi.org/10.2307/3033568

Cramm, J. M., Koolman, X, \& Nieboer, A. P. (2011). Socioeconomic status and self-reported tuberculosis: A multilevel analysis in a low-income township in the Eastern Cape, South Africa. African Journal of Public Health.

Cramm, J. M., \& Nieboer, A. P. (2011a). The influence of social capital and socio-economic conditions on self-rated health among residents of an economically and health-deprived South African township. International Journal for Equity in Health. 10:51. http://dx.doi.org/10.1186/1475-9276-10-51 
Cramm, J. M., \& Nieboer, A. P. (2011b). The relationship between (stigmatizing) ideas and the lay public preferences regarding tuberculosis treatment in the Eastern Cape, South Africa. International Journal for Equity in Health, 10(1), 2. http://dx.doi.org/10.1186/1475-9276-10-2

Cramm, J. M., Møller, V., \& Nieboer, A. P. (2010a). Individual- and neighbourhood-level indicators of subjective well-being in a small and poor Eastern Cape township: The effect of health, social capital, marital status, and income. Social Indicators Research. 105 (3) 581-593. http://dx.doi.org/10.1007/s11205011-9790-0

Cramm, J. M., Møller, V., Finkenflügel, H. J. M., \& Nieboer, A. P. (2010). TB treatment initiation and adherence in a South African community influenced more by perceptions than by knowledge of tuberculosis. BMC Public Health, 10(72), 1-8.

Cramm, J. M., Møller, V., \& Nieboer, A. P. (2010b). Improving subjective well-being of the poor in the Eastern Cape. Journal of Health Psychology, 15, 1012-1019. http://dx.doi.org/10.1177/1359105310367833

Cramm J. M., van Exel, J., Møller, V., \& Finkenflügel, H. J. M. (2010). Patient views on determinants of compliance with tuberculosis treatment in the Eastern Cape, South Africa: An application of Qmethodology. Patient, 3(3), 159-172.

Diener, E. (1994). Assessing subjective well-being: Progress and opportunities. Social Indicators Research, 31, 103-157. http://dx.doi.org/10.1007/BF01207052

Diener, E., \& Biswas-Diener, R. (2002). Will money increase subjective well-being? Social Indicators Research, 57, 119-169. http://dx.doi.org/10.1023/A:1014411319119

Diener, E., \& Lucas, R. E. (2000). Explaining differences in societal levels of happiness: Relative standards, need fulfillment, culture, and evaluation theory. Journal of Happiness Studies, 1, 41-78. http://dx.doi.org/10.1023/A:1010076127199

Diener, E., \& Oishi, S. (2000). Money and happiness: Income and subjective well-being across nations. In E. Diener \& E. M. Suh (Eds.), Subjective Well-Being Across Cultures. Cambridge MA: MIT Press.

Diener, E., \& Scollon, C. N. (2003). Subjective well-being is desirable, but not the summum bonum. Paper presented at the Workshop on Well-Being, University of Minnesota.

Diener, E., Emmons, R. A., Larsen, R. J., \& Griffen, S. (1985a). The Satisfaction with Life Scale. Journal of Personality Assessment, 49, 71-75. http://dx.doi.org/10.1207/s15327752jpa4901_13

Diener, E., Horwitz, J., \& Emmons, R. A. (1985b). Happiness of the very wealthy. Social Indicators Research, 16, 263-274. http://dx.doi.org/10.1007/BF00415126

Diener, E., Kahneman, D., Tov, W., \& Arora, R. (2010). Income's association with judgment of life versus feelings. In E. Diener, D. Kahneman, \& J. Helliwell (Eds.), International Differences in Well-Being (pp. 3-15). New York, NY: Oxford University Press. http://dx.doi.org/10.1093/acprof:oso/9780199732739.003.0001

Diener, E., Sandvik, E., Seidlitz, L., \& Diener, M. (1993). The relationship between income and subjective well-being: Relative or absolute? Social Indicators Research, 28, 195-223. http://dx.doi.org/10.1007/BF01079018

Diener, E., Suh, E., Lucas, R., \& Smith, H. (1999). Subjective well-being: Three decades of progress. Psychological Bulletin, 125, 276-302. http://dx.doi.org/10.1037/0033-2909.125.2.276

Dolan, P., Peasgood, T., \& White, M., (2008). Do we really know what makes us happy? A review of the economic literature on the factors associated with subjective well-being. Journal of Economic Psychology, 29, 94-122. http://dx.doi.org/10.1016/j.joep.2007.09.001

Easterlin, R. A. (1974). Does economic growth improve the human lot? Some empirical evidence. In P. A. David \& M. W. Reder (Eds.), Nations and Households in Economic Growth (pp. 89125). New York, NY: Academic Press.

Easterlin, R. A. (2000). Income and happiness: Towards a unified theory. The Economic Journal, 111, 465484. http://dx.doi.org/10.1111/1468-0297.00646

Fahey, T., Whelan, C. T., \& Maitre, B. (2005). First European Quality of Life Survey: Income Inequalities and Deprivation. Luxembourg: Office for Official Publications of the European Communities.

Frey, B., \& Stutzer, A. (2002). Happiness and Economics. Princeton, NJ: Princeton University Press.

Grootaert, C. (2002). Social Capital, Household Welfare and Poverty in Indonesia (Policy Research Working Paper No. 2148). Washington, DC: The World Bank. 
Haggerty, M. R., Cummins, R. A., Ferriss, A. L., Land, K., Michalos, A. C., Peterson, M., Sharpe, A., Sirgy, J., \& Vogel, J. (2001). Quality of life indexes for national policy: Review and agenda for Research. Social Indicators Research, 55, 1-96. http://dx.doi.org/10.1023/A:1010811312332

Hoorn, A. (2007). A short introduction to subjective well-being: Its measurement, correlates and policy use. http://www.oecd.org/dataoecd/16/39/38331839.pdf.

Idler, E. L., \& Benyamanini, Y. (1997). Self-rated health and mortality: A review of twenty-seven community studies. Journal of Health and Social Behavior, 38, 21-37. http://dx.doi.org/10.2307/2955359

Idler, E. L., \& Kasl, S. V. (1995). Self-ratings of health: Do they predict change in functional ability? Journal of Gerontology: Social Sciences, 50, 344-353. http://dx.doi.org/10.1093/geronb/50B.6.S344

Kahneman, D. (1999). Objective happiness. In D. Kahneman, E. Diener, \& N. Schwarz (Eds.), Well-Being: The Foundations of Hedonic Psychology (pp. 3-25). New York, NY: Russell Sage Foundation.

Kashdan, T. B. (2004). The assessment of subjective well-being (Issues raised by the Oxford Happiness Questionnaire). Personality and Individual Differences, 36, 1225-1232. http://dx.doi.org/10.1016/S01918869(03)00213-7

Keck, W., \& Krause, P. (2007). How does European Union enlargement affect social cohesion? In R. J. Estes (Ed.), Advancing Quality of Life in a Turbulent World (pp. 3-24). Dordrecht, NL: Springer.

Kessler, R., Turner, J., \& House, J. (1988). Effects of unemployment on health in a community survey: Main, modifying, and mediating effects. Journal of Social Issues, 44, 69-85. http://dx.doi.org/10.1111/j.1540-4560.1988.tb02092.x

Lachman, M. E., \& Weaver, S. L. (1998). The sense of control as a moderator of social class differences in health and well-being. Journal of Personality and Social Psychology, 74(3), 763-777. http://dx.doi.org/10.1037/0022-3514.74.3.763

Larsen, J. T. \& McKibban, A. R. (2008). Is happiness having what you want, wanting what you have, or both? Psychological Science, 19, 371-377. http://dx.doi.org/10.1111/j.1467-9280.2008.02095.x

Lucas, R. E., Diener, E., \& Suh, E. (1996). Discriminant validity of well-being measures. Journal of Personality and Social Psychology, 71, 616-628. http://dx.doi.org/10.1037/0022-3514.71.3.616

Marks, N., Abdallah, S., Simms, A., \& Thompson, S. (2006). The Happy Planet Index. London, UK: New Economics Foundation.

Møller, V. (2007). Living in Rhini. A 2007 Update on the 1999 Social Indicators Report (Research Report Series No. 14). Grahamstown, RSA: Institute of Social and Economic Research.

Møller, V. (2008). Destigmatising TB in the Time of HIVIAIDS. Attitudes, Beliefs, and Recommendations from an Eastern Cape Community (Research Report Series No. 15). Grahamstown, RSA: Institute of Social and Economic Research.

Møller, V., \& Erstad, I. (2007). Stigma associated with tuberculosis in a time of HIV/AIDS: Narratives from the Eastern Cape, South Africa. South African Sociological Review, 38, 103-119. http://dx.doi.org/10.1080/21528586.2007.10419170

Møller, V., Erstad, I., \& Zani, D. (2009). Drinking, smoking, and morality: Do 'Drinkers and Smokers' constitute a stigmatised stereotype or a real TB risk factor in the time of HIV/AIDS? Social Indicators Research, 98, 217-238.

Møller, V., Erstad, I., Cramm, J. M., Nieboer, A. P., Finkenflügel, H. J. M., Radloff, S., Ndoro, T., Kwizera, S. A. (2011). Delays in presenting for tuberculosis treatment associated with fear of learning one is HIV positive. African Journal of AIDS Research, 10(1), 25-36. http://dx.doi.org/10.2989/16085906.2011.575545

Mossey, J. M. \& Shapiro, E. (1982). Self-rated health: A predictor of mortality among the elderly. American Journal of Public Health, 72, 800-808. http://dx.doi.org/10.2105/AJPH.72.8.800

Nieboer, A. \& Lindenberg, S. (2002). Substitution, buffers and subjective well-being: A hierarchical approach. In E. Gullone \& R.A. Cummins (Eds.), The Universality of Subjective Well-Being Indicators (pp.175-89). Dordrecht, NL: Kluwer Academic Publishers.

Nieboer, A., Lindenberg, S., Boomsma, A., \& Van Bruggen, A. C. (2005). Dimensions of well being and their measurement: The SPF-IL Scale. Social Indicators Research, 73, 313-353.

http://dx.doi.org/10.1007/s11205-004-0988-2 
Noble, M., Barnes, H., Wright, G., \& Roberts, B. (2010). Small area indices of multiple deprivation in South Africa. Social Indicators Research, 95, 281-297. http://dx.doi.org/10.1007/s11205-009-9460-7

Pavot, W., \& Diener, E. (1993). Review of Satisfaction with Life Scale. Psychological Assessment, 5, $164-172$. http://dx.doi.org/10.1037/1040-3590.5.2.164

Powdthavee, N. (2007). Are there geographical variations in the psychological cost of unemployment in South Africa? Social Indicators Research, 80, 629-652. http://dx.doi.org/10.1007/s11205-006-0013-z

Requena, F. (2003). Social capital, satisfaction, and quality of life in the workplace. Social Indicators Research, 61, 331-360. http://dx.doi.org/10.1023/A:1021923520951

Shields, M. \& Wheatley Price, S. (2005). Exploring the economic and social determinants of psychological well-being and perceived social support in England. Journal of the Royal Statistical Society (Series A), 168, 513-538. http://dx.doi.org/10.1111/j.1467-985X.2005.00361.x

Shields, M., Wheatley Price, S., \& Wooden, M. (2008). Life satisfaction and the economic and social characteristics of neighbourhoods. Journal of Population Economics, 22, 421-443. http://dx.doi.org/10.1007/s00148-007-0146-7

Stutzer, A. (2004). The role of income aspirations in individual happiness. Journal of Economic Behavior and Organization, 54, 89-109. http://dx.doi.org/10.1016/j.jebo.2003.04.003

Stutzer, A. \& Lalive, R. (2004). The role of social work norms in job searching and subjective well-being. Journal of the European Economic Association, 2, 696-719. http://dx.doi.org/10.1162/1542476041423331

Wen, M., Browning, C. R., \& Cagney, K. A. (2003). Poverty, affluence, and income inequality: Neighborhood economic structure and its implications for health. Social Science $\mathcal{E}$ Medicine, 57, 843860. http://dx.doi.org/10.1016/S0277-9536(02)00457-4

Wilkinson, R. G., \& Pickett, K. E. (2006). Income inequality and population health: A review and explanation of the evidence. Social Science $\mathcal{E}$ Medicine, 62, 1768-1784.

Winkelman, R. (2009). Unemployment, social capital, and subjective well-being. Journal of Happiness Studies, 10, 421-430. http://dx.doi.org/10.1007/s10902-008-9097-2

Yip, W., Sybramanian, S. V., Mitchell, A. D., Lee, D. T. S., Wang, J., \& Kawachi, I. (2007). Does social capital enhance health and well-being? Evidence from rural China. Social Science E Medicine, 64, 3549. http://dx.doi.org/10.1016/j.socscimed.2006.08.027 